\title{
Atypical Preeclampsia: A Review
}

\author{
Sreelakshmi Kodandapani* and Ashwini h Pai \\ Department of OBG, Subbaiah Medical College, India
}

Submission: October 30, 2018 ; Published: November 21, 2018

*Corresponding author: Sreelakshmi Kodandapani, Department of OBG, Professor \& Head of the Department, Subbaiah Medical College, India

\begin{abstract}
Hypertensive disorders are the most common medical disorders in pregnancy with incidence independent of environmental and ethnic influences. Fetal and maternal morbidity including progressing to eclampsia varies from country to country. Early recognition, diagnosis remains the main the step in management. Eclampsia without typical signs and symptoms of prodrome is called unheraded eclampsia. Maternal and perinatal morbidity and mortality depend upon the number, type and recurrence of seizures in eclampsia, hence definitely high in developing countries and low in developed nations.
\end{abstract}

Keywords: Atypical preeclampsia; Preeclampsia; Eclampsia

\section{Introduction}

Hypertensive disorders are the most common medical disorders in pregnancy. They rank second in maternal death annually [1]. Incidence of preeclampsia is the same (5$10 \%)$ throughout the world indicating that the disorder is independent of environmental and ethnic influences. However fetal and maternal morbidity including progressing to eclampsia varies from country to country directly correlating to quality and accessibility of antenatal care. In developing countries, preeclampsia/eclampsia is responsible for 50000 deaths annually [2].

Early recognition, diagnosis remains the main step in management. But early diagnosis is difficult due to great variability in clinical presentation. Typical presentation of elevated blood pressure, proteinuria and generalized edema are uncommon. Edema is neither considered necessary nor sufficient for diagnosis, and if present cannot be ignored also. Hypertension of 140/90 mmHg remains the cut-off but cannot be considered entirely benign as $40 \%$ of them may progress to proteinuric preeclampsia.

Although 300mg/24 urine is considered important for proteinuria, nonproteinuric preeclampsia is not benign and may not represent a separate entity from preeclampsia [3]. In an analysis of all cases of eclampsia in UK in 1992, it was noted that in 38\% cases seizure occurred without prior documentation of either hypertension or proteinuria, hence concluding that hypertension and proteinuria are neither essential nor important for diagnosis of preeclampsia. The clinical presentation of preeclampsia is extremely vague; the only presenting element is the patient's statement that she doesn't feel well.

\section{Definition}

Table 1

\begin{tabular}{|c|}
\hline Atypical preeclampsia \\
\hline Gestational hypertension +1 of the \\
\hline following items: \\
\hline Symptoms of preeclampsia \\
\hline 1.Hemolysis \\
\hline 2.Thrombocytopenia (_ $100,000 / \mathrm{mm} 3$ ) \\
\hline 3.Elevated liver enzymes (2 times the \\
\hline upper limit of the normal value for \\
\hline aspartate aminotransferase or alanine \\
\hline aminotransferase) \\
\hline Gestational proteinuria +1 of the \\
\hline following items: \\
\hline 1.Symptoms of preeclampsia \\
\hline 2.Hemolysis \\
\hline 3.Thrombocytopenia \\
\hline 4.Elevated liver enzymes \\
\hline Early signs and symptoms of \\
\hline preeclampsia-eclampsia at $<20$ weeks \\
\hline Late postpartum preeclampsia-eclampsia $>48 \mathrm{~h}$ of delivery \\
\hline
\end{tabular}

Atypical preeclampsia is defined as any clinical presentation of preeclampsia $<20$ weeks of gestation and $>48 \mathrm{~h}$ after delivery. Also, in variability as described in Table 1 . When this clinical presentation is described, capillary leak syndrome should also be known. Capillary syndrome is ascites, pulmonary edema, proteinuria associated with multiorgan dysfunction. Therefore, 
patients of capillary leak syndrome should be evaluated for liver enzymes and platelets also [4-9].

Women with proteinuria and normal blood pressure: women with normal blood pressure and proteinuria of $3+$ especially persistent after 8 weeks after delivery needs detailed evaluation. They need evaluation to rule out lupus nephritis and sometimes even renal biopsy. Moreover, women with proteinuria and cardiorespiratory symptoms need evaluation such as cardiac failure or peripartum cardiopathy. The challenge of severe atypical preeclampsia: As early as 1992, in United Kingdom the analysis of all cases of eclampsia concluded that "hypertension is neither the only nor necessarily the most important signs of preeclampsia" $[10,11]$.

In the absence of the classical presentation, preeclampsia may imitate many non-obstetric disorders and may be seen by subspecialists. Reports of the disease misdiagnosed as viral hepatitis, cholangitis, lupus erythematosus, upper gastrointestinal ulceration, idiopathic thrombocytopenia, neurologic disorders. Etc [12].

Goodlin described "preeclampsia as a good imitator"

\section{Intracranial complications of preeclampsia}

Hypertensive encephalopathy is an over perfusion syndrome leading to cerebral infarction and bleeding. It is also known as PRES: posterior Encephalopathy syndrome. This may cause permanent white matter loss. Dural sinus thrombosis, cerebral vasculitis or benign postpartum angiopathy, characterized by segmental narrowing of cerebral arteries (chain of beads), a finding is usually absent in eclampsia [13]. Call-Fleming syndrome is a clinical syndrome characterized by reversible multifocal brain ischemia due to multilocular segmental narrowing of large and medium sized cerebral arteries. They present as generalized headache, seizures, cortical blindness, visual field defects, confusion, aphasia, hemiparesis or ataxia [14].

\section{Atypical preeclampsia in epidemiologic and clinical context}

Maternal morbidity and mortality in preeclampsia are influenced by occurrence, severity, type and number of seizures. Seizures may lead to neurological damage, leading to severe maternal hypoxia, trauma and aspiration pneumonia. Permanent white matter loss is also documented in women without clinical neurologic deficits. A significant proportion of women don't demonstrate signs of preeclampsia before eclampsia and this condition is called unheralded eclampsia.

\section{Summary}

\section{Pathophysiology}

- Abnormal placentation leads to placental insufficiency and fetal growth restriction
- Increased inflammatory activity gives rise to widespread damage to the vascular endothelium

- This is compounded by a heightening of the immunological state through circulating leucocytes, similar to sepsis

- This inflammatory response is probably caused by 'placental debris' leading to systemic inflammation and vascular dysfunction

\section{Prevention}

- Low-dose aspirin is a cost-effective tool in the prevention of pre-eclampsia and should be recommended for use in moderate to high risk women in early pregnancy.

\section{Proteinuria}

- Estimations of levels of proteinuria in women with pre-eclampsia do not correlate with maternal and fetal outcomes

- Once proteinuria has been diagnosed there is no benefit in repeating the test

\section{Pre-eclamptic toxemia screen}

- Platelet count, transaminases and serum creatinine are good predictors of disease progression in women who already have pre-eclampsia

- Rising uric acid does not add any additional information to these tests

\section{Treatment}

- Labetalol is now considered the first-line antihypertensive agent

- Patients with pre-eclampsia should be admitted to hospital, have regular blood pressure readings (at least four times a day), testing for proteinuria and monitoring of blood parameters, namely kidney function, electrolytes, full blood count, transaminases and bilirubin

\section{Umbilical artery Doppler velocimetry}

- In high-risk pregnancies, including those complicated by hypertensive disease, the use of umbilical artery Doppler velocimetry reduces perinatal morbidity and mortality.

- It helps in deciding timing of delivery, especially when enddiastolic flow is absent.

\section{Timing of delivery}

- There is no evidence of any benefit in prolonging pregnancy beyond 34 weeks in severe pre-eclampsia

\section{Magnesium sulfate}

- Magnesium sulfate is the anticonvulsant of choice in the treatment of eclampsia. 
- It also prevents eclampsia and should also be considered in women with severe pre-eclampsia who are in a critical care setting if birth is planned within $24 \mathrm{~h}$.

\section{Fluid balance}

- Volume expansion should not be used in women with severe pre-eclampsia.

Hemolysis, elevated liver enzymes \& low platelets syndrome

- Corticosteroids have no beneficial effect on the clinical outcome of patients with hemolysis, elevated liver enzymes and low platelets syndrome.

\section{Postnatal management}

- Women who developed severe pre-eclampsia requiring delivery before 34 weeks have a $25 \%$ risk of the condition recurring in the next pregnancy.

\section{Conclusion}

I. Use of antihypertensives, relevant investigations and treatment has improved the outcome of pre-eclamptic patients.

II. Blood markers that increase the risk of development of the disease are already present in the first trimester.

III. The use of aspirin, in conjunction with the use of the first trimester blood markers, will help reduce the number of women requiring close monitoring, hospitalization and development of the more severe forms of the disease.

\section{References}

1. Paxton A, Wardlaw T (2011) Are we making progress in maternal mortality? N Eng J Med 364(21): 1990-1993.

2. Roberts JM, Villar J, Arulkumaran S (2002) Preventing and treating eclamptic seizures. BMJ 325(7365): 609-610.
3. Brown MA, Lindheimer MD, de Swiet M, Van Assche A, Moutquin JM (2001) The classification and diagnosis of the hypertensive disorders of pregnancy. Statement from the International society for the study of Hypertension in Pregnancy (ISSHP). Hypertens Pregnancy 20(1): IXIXV.

4. Sibai BM, Stella CL (2009) Diagnosis and management of atypical preeclampsia eclampsia. Am J Obstet Gynecol 200(5): 481.e1-481.e7.

5. Brown MA1, Hague WM, Higgins J, Lowe S, McCowan L, et al. (2000) The detection, investigation, and management of hypertension in pregnancy: full consensus statement of recommendations from the Council of Australian Society of the study of hypertension in pregnancy. Aust N Z J Obstet Gynaecol 40(2): 139-155.

6. Sibai BM (2004) Diagnosis, controversies and management of the HELLP syndrome. Obstet Gynecol 103(5): 981-991.

7. Sibai BM (2005) Diagnosis, differential diagnosis and management of eclampsia. Obstet Gynecol 105(2): 402-410.

8. Brown MA, Buddle ML (1996) Hypertension in pregnancy: maternal and fetal outcomes according to laboratory and clinical features. Med J Aust 165(7): 360-365.

9. Murakami S, Saitoh M, Kubo T, Koyama T, Kobayashi M (2000) Renal disease in women with severe preeclampsia or gestational proteinuria. Obstet Gynecol 96(6): 945-9.

10. Douglas KA, Redman CW (1994) Eclampsia in the United Kingdom. BMJ 309(6966): 1395-400.

11. Goodlin RC (1991) Preeclampsia as the great imposter. Am J Obstet Gynecol 164(6): 1577-1580.

12. Neurdecker S, Stock K, Kranianski M (2006) Call- Fleming Postpartum angiopathy in the puerperium. Obstet gynecol 107(2): 446-449.

13. Call GK, Fleming MC, Sealfon S, Levine H, Kistler JP, et al. (1988) Reversible cerebral segmental vasoconstriction. Stroke 19(9): 1159-1570.

14. Ciantar E, Walker JJ (2011) Pre-eclampsia, severe pre-eclampsia and hemolysis, elevated liver enzymes and low platelets syndrome: what is new? Women's Health 7(5): 555-569.

\begin{tabular}{|l|}
\hline \multicolumn{1}{|c|}{ Your next submission with Juniper Publishers } \\
will reach you the below assets \\
- Quality Editorial service \\
- Swift Peer Review \\
- Reprints availability \\
- E-prints Service \\
- Manuscript Podcast for convenient understanding \\
- Global attainment for your research \\
- Manuscript accessibility in different formats \\
( Pdf, E-pub, Full Text, Audio) \\
- Unceasing customer service \\
Track the below URL for one-step submission \\
https://juniperpublishers.com/online-submission.php \\
\hline
\end{tabular}

